\title{
An Application of Gamma Distribution to the Income Distribution and the Estimation of Potential Food Demand Functions
}

\author{
Shunsuke Mori'1, Daichi Nakata ${ }^{2}$, Tomohiro Kaneda ${ }^{2}$ \\ ${ }^{1}$ Department of Industrial Administration, Faculty of Science and Technology, Tokyo University of Science, \\ Noda, Japan \\ ${ }^{2}$ Hitachi, Ltd., Tokyo, Japan \\ Email: sh mori@rs.noda.tus.ac.jp
}

Received 17 August 2015; accepted 21 September 2015; published 24 September 2015

Copyright (C) 2015 by authors and Scientific Research Publishing Inc.

This work is licensed under the Creative Commons Attribution International License (CC BY). http://creativecommons.org/licenses/by/4.0/

(c) () Open Access

\section{Abstract}

Poverty and hunger are the central issues against the sustainable development. Today, more than 800 million people are suffering from insufficient nutrition according to FAO (FAO, 2010). However, on the other hand, it is often pointed out that the per capita food production already meets the demand for the per capita food requirement. The above contradictory observation suggests that many people cannot access the food market because of the low income. The availability of electricity and other energy is also the case. Since these issues are mainly caused by the inequity of income distribution, its quantitative analysis is indispensable to evaluate the societal policy towards the sustainable future. However, since the existing indicators such as Gini coefficients do not represent the income distribution explicitly, they fail to assess the effects of social policy for the improvement of purchasing power of poor people. Population of absolute poverty who gets less than 1.25 US dollar per day is also provided by World Bank. This indicator does not show the distribution pattern of middle to high income classes. The authors would thus point out the need for an alternative method. This paper describes an application of Gamma distribution to the income distribution patterns. The parameters are statistically estimated based on the income quintile data provided by World Bank. The results show how the income distribution has changed historically by country. Based on the future income distribution and the simulation results of the author's crop market model, we evaluate the share of people who cannot afford the major crop. The authors also propose a procedure to estimate the potential food demand function considering the income distribution changes, suggesting that the future demand could be affected by not only the per-capita income growth but the income distribution changes. 
Keywords

\section{Income Distribution, Gamma Distribution, Income Quintile, Potential Demand Function}

\section{Introduction}

\subsection{Background}

Poverty and hunger are the central issues against the sustainable development. Today, more than 800 million people are suffering from insufficient nutrition [1]. On the other hand, it is often pointed out that the per capita food production already meets the demand for the per capita food requirement. The above contradictory observation suggests that many people cannot access the food market because of the low income. The availability of electricity and other energy is also the case. Since these issues are mainly caused by the inequity of income distribution, its quantitative analysis is indispensable to evaluate the societal policy towards the sustainable future. From the wider and historical views, Picketty [2] emphasized the distribution issues in the capitalism driven society.

Although the income distribution issue is well recognized towards the sustainable world, the investigations on the indicator to represent the inequity and its outcome are limited. For instance, the existing indicator such as Gini coefficients [3] fails to explicitly represent the distribution of people who are suffering from insufficient income and thus the outcome of redistribution policy is not quantitatively evaluated. Another indicator, share of the population of absolute poverty who gets less than 1.25 US dollar per day in Gross National Income in Purchasing Power Parity (GNI-PPP) is also provided by World Bank [4]. The absolute poverty level is here defined while the fraction of near poverty class is not here represented. When one consider the education and the medical support policies for the low income people, the distribution pattern of middle and high income classes their changes should be also taken into account.

The above observation on the existing indicators shows us two terms: first, since the income distribution issue represents both the fraction of absolute poor and the relative inequity status of the whole society, we need a new indicator which shows the inequality both in absolute number and in relative share profile. Second, we have to develop a method to estimate the parameters for the indicator empirically.

As can be supposed, income distribution patterns ranges from a society which consists of "minor rich people" and "major poor people" to a society which consists of "major middle income people" with small rich and poor. The new method should cover these different profiles by a unified formulation with different parameters. In this paper, we propose a new method to estimate the income distribution applying Gamma distribution function based on the income share data given by World Bank [5]. The reason to employ Gamma distribution function is as follows: first, Gamma distribution function can represent profiles with different skewness from "monotonically decreasing" density function which implies "minor rich and major poor" society to "bell-shaped" one suggesting "major middle" society by shape parameter. Second, since Gamma distribution function contains two parameters, i.e. shape parameter and scale parameter, one can expect that they can be estimated based on the limited data. In Section 2, we describe the data source for the income distribution followed by the method to estimate the parameters empirically. In section 3 we show the results of Gamma distribution to 148 countries and 627 data sets. We then expand the method to see the future income distribution changes in Section 4 . The projection of people in hunger defined by a population who cannot afford the required food is also calculated by applying a crop market model developed by the authors [6].

\subsection{The Need for the Income Distribution for the Demand Estimation}

In this subsection, we show an example of a problem caused by the aggregation.

A question whether future food production can meet the future demand under the population and the economic growth of developing regions is still controversial. While Lester Brown [7] emphasizes a pessimistic view, IFPRI emphasizes a possibility to overcome the hunger in 2020 VISION [8] by a world corporation and action. Kawashima [9] concludes that the food supply shortage is unlikely based on his saturating food demand estimation and the potential cropland. Kawashima [9] and Lomborg [10] attribute the hunger issue to the political is- 
sues rather than the production potential especially in African countries. Since it is generally acceptable that the nutrition intake demand is saturated as the income increases, the global economic growth in developing world would lower the additional demand for food.

However, it should be pointed out that the future food demand in the above debate is often estimated based on the relationship between per-capita demand and per-capita income regardless of the domestic income distribution. Such an aggregated view often fails to see the effects of income structural changes. Let us show an example how the income distribution distorts the "aggregated" indicator in Table 1. Suppose the case that there are "rich" and "poor" people in a region and that population, income and food demand of poor people are 10.0, 1.0 and 1.0 while those of rich are 1.0, 10.0 and 20.0, respectively at period T. Thus, per capita income and food demand are 2.7 and 1.8, respectively. Suppose that the population and the per capita income of poor people increase by $15 \%$ and $20 \%$ in one period and those of rich people are unchanged. Then, at period $\mathrm{T}+1$, the average of the per capita income of this region decreases from 2.73 to 2.70 ( $-0.85 \%$ growth) even if economic growth significantly contributes to the poor people. On the other hand, assuming the income elasticity of food demand to be 0.8 , the per-capita food demand increases by only $2.55 \%$ even if the total demand for food increases $16.53 \%$. Furthermore, income elasticity of aggregated number shows negative value. This case, which is no more than an example of statistical problem, could appear in the developing region. Thus we can see the importance of focusing on the income distribution and the estimation of demand taking into account its change.

\section{Method of Income Distribution Estimation}

\subsection{Income Distribution Data Source}

In this study, we employ the Percentage share of income or consumption provided by World Bank. This indicator shows the share that accrues to subgroups of population indicated by deciles or quintiles which are based on primary household survey data obtained from government statistical agencies and World Bank country departments [3]-[5] [11]-[14]. For many countries, income share of seven quantiles is available. For US and Japan, we extract the data US Department of Commerce [15] and Ministry of Internal Affairs and Communication [16] which represent the share of households. For some countries, this data source covers time series. For example, 1989-2007 data is available for Brazil. As a whole, we gathered the income distribution quintile data for 148 countries and 627 points. Multiplying the share by total GDP in purchasing power parity based, we can estimate the income share of category in absolute term.

\subsection{Applying Gamma Distribution Function}

Profile of income distribution is expected to be asymmetric with long tail rather than the bell-shaped symmetric

Table 1. Problem of aggregation-example.

\begin{tabular}{|c|c|c|c|c|c|c|c|}
\hline & & \multicolumn{3}{|c|}{$\mathbf{T}$} & \multicolumn{3}{|c|}{$\mathbf{T}+\mathbf{1}$} \\
\hline & & Rich & Poor & Total & Rich & Poor & Total \\
\hline & Population & 1.0 & 10.0 & 11.0 & 1.0 & 11.5 & 12.5 \\
\hline & Per Capita Income & 20.0 & 1.0 & 2.73 & 20.0 & 1.2 & 2.70 \\
\hline & Total Income & 20.0 & 10.0 & 30.0 & 20.0 & 12.7 & 33.8 \\
\hline & Per Capita Food & 10.0 & 1.0 & 1.82 & 10.0 & 1.16 & 1.86 \\
\hline & Total Food Demand & 10.0 & 10.0 & 20.0 & 10.0 & 13.3 & 23.3 \\
\hline \multirow{5}{*}{ Growth Rate } & Population & $0.00 \%$ & $15.00 \%$ & & $0.00 \%$ & $15.00 \%$ & $13.64 \%$ \\
\hline & Per Capita Income & $0.00 \%$ & $20.00 \%$ & & $0.00 \%$ & $20.00 \%$ & $-0.85 \%$ \\
\hline & Total Income & & & & $0.00 \%$ & $38.00 \%$ & $12.67 \%$ \\
\hline & Per Capita Food & & & & $0.00 \%$ & $15.70 \%$ & $2.55 \%$ \\
\hline & Total Food Demand & & & & $0.00 \%$ & $33.06 \%$ & $16.53 \%$ \\
\hline Elasticity & Csmp/Cap & 0.0 & 0.80 & & & & \\
\hline
\end{tabular}


figure as is suggested by the international comparison. In this study, we employ a Gamma distribution function which can represent both asymmetric shape with long-tail and quasi-symmetric profile under identical mean value. Equation (1) is the general form of Gamma distribution with two parameters, $\alpha$ and $\beta$. The product of parameters $\alpha \beta$ represents the mean value.

$$
f(x, \alpha, \beta)=\frac{1}{\beta^{\alpha} \Gamma(\alpha)} x^{\alpha-1} \mathrm{e}^{-\frac{x}{\beta}}
$$

The cumulative distribution is often written by Equation (2) replacing $x$ by normalized value.

$$
G(Z ; \alpha)=\int_{0}^{Z} \frac{1}{\Gamma(\alpha)} z^{\alpha-1} \exp (-z) \mathrm{d} z \text { where } z=\left(\frac{x}{\beta}\right)
$$

Figure 1 shows the profiles of Gamma distribution function with different parameters and identical mean value, i.e. 24.0. As $\alpha$ becomes smaller, the peak of distribution moves left and converges exponential distribution when $\alpha=1$. The cases with $0<\alpha<1(x>0)$ show similar shape to the exponential distribution. Distribution with large $\alpha$ represents the converging income distribution and diminishing inequity.

\subsection{Estimation Procedure of Gamma Distribution Parameters}

It is known that the Gamma distribution (1) gives mean value and variance $\alpha \beta$ and $\alpha \beta^{2}$, respectively. However, one cannot estimate these values precisely based on the quintile data. In this study, we propose an alternative procedure employing nonlinear optimization method.

Let $k, T_{k}, S_{k}, M_{k}$ and $M^{*}$ denote the $k$-th income class, share of income of class $k$, share of population of class $k$, and average income of class $k$, and average national income, respectively. $X_{k}$ and $T S_{k}$ represent the upper border income of class $k$ and cumulative share of population of class $k$ defined as follows:

$$
T S_{k}=\int_{0}^{X_{k}} f(x ; \alpha, \beta) \mathrm{d} x=G\left(\left(\frac{X_{k}}{\beta}\right) ; \alpha\right)=G\left(Z_{k} ; \alpha\right)
$$

Then the ratio of cumulative average income under $N$-quantile to the total average income $M^{*}$ can be formulated by

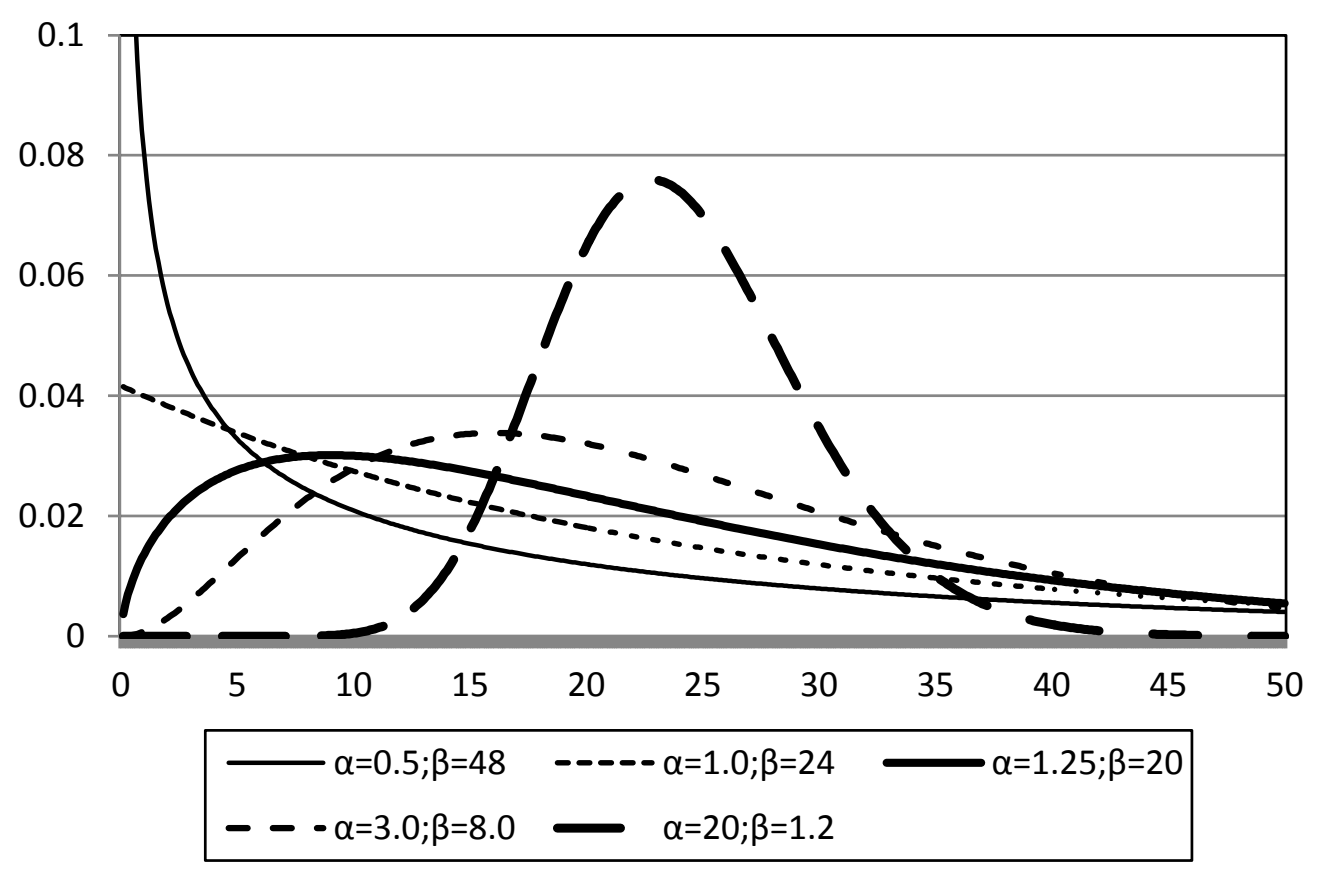

Figure 1. Example of Gamma distribution profiles. 


$$
\begin{aligned}
\frac{\sum_{k=1}^{N} S_{k} M_{k}}{M^{*}} & =\frac{\int_{0}^{X_{N}} x \times f(x ; \alpha, \beta) \mathrm{d} x}{\int_{0}^{\infty} x \times f(x ; \alpha, \beta) \mathrm{d} x}=\frac{\int_{0}^{X_{N}} \frac{1}{\beta^{\alpha} \Gamma(\alpha)} x^{\alpha} \mathrm{e}^{-\frac{x}{\beta}} \mathrm{d} x}{\int_{0}^{\infty} \frac{1}{\beta^{\alpha} \Gamma(\alpha)} x^{\alpha} \mathrm{e}^{-\frac{x}{\beta}} \mathrm{d} x}=\frac{1}{\left(\frac{\Gamma(\alpha+1)}{\Gamma(\alpha)}\right)} \int_{0}^{X_{N}} \frac{1}{\beta^{\alpha} \Gamma(\alpha)} x^{\alpha} \mathrm{e}^{-\frac{x}{\beta}} \mathrm{d} x \\
& =\int_{0}^{X_{N}} \frac{1}{\beta^{\alpha} \Gamma(\alpha+1)} x^{\alpha} \mathrm{e}^{-\frac{x}{\beta}} \mathrm{d} x=G\left(\left(\frac{X_{N}}{\beta}\right) ; \alpha+1\right)=G\left(Z_{N} ; \alpha+1\right)
\end{aligned}
$$

Thus, we can estimate the parameter $\alpha$ and the normalized border of class $N$, i.e. $Z_{N}$, applying least square estimation

$$
\min _{\alpha, Z_{N}} \sum_{N}\left(T S_{N}-G\left(Z_{N} ; \alpha\right)\right)^{2}+\left(\frac{\sum_{k=1}^{N} S_{k} M_{k}}{M^{*}}-G\left(Z_{N} ; \alpha+1\right)\right)^{2}
$$

Then $\beta$ and $X_{N}$ can be obtained from $M^{*}=\alpha \beta$ and $X_{N}=Z_{N} \beta$.

It should be noted that the statistical properties of the estimators given by the above is not yet clear although the fitness of above procedure provides high as shown in the next section. This statistical rationale remains of the above procedure as a future subject.

\section{Results of Gamma Distribution and Projection of Future Poverty and Hunger}

In this study, we apply the above method to the 148 countries to see the properties of the income distribution and their dynamic changes. Then these are applied to estimate the future poverty and hunger.

\subsection{Gamma Distribution Properties}

The example of the estimated parameters and fitness in $R^{2}$ between the data and the estimated income share is shown in the Figure Annex. Standard deviations of the estimated population share of the income quantile are also shown. The scale parameter $\beta$ is calculated based on the GNI-PPP in hundred current international dollars [13]. As is observed, most of the $R^{2}$ show around 1.000. In fact, 622 of 627 points show more than 0.997 of $R^{2}$ and other 5 cases give around 0.886 where the income share of class 1 (lowest $10 \%$ income share) is estimated to be zero. The standard deviations of population share, which are $10 \%$ or $20 \%$, show low in the OECD and the former central planned economy countries, while those in South American and Asian countries are relatively high but still lower than 0.025. Belarus in 1993 shows highest deviation, i.e. 0.055, where the income share of 1-quantile is estimated to be zero. We conclude that the procedure proposed in this paper provides fairly good fitness.

Some results are exhibited in Figures 2-9.

Although the Gamma distribution parameters spread broadly among countries, these figures do not clearly show the differences of distributions. However, the Gamma distribution profiles of Japan, USA and Brazil in Figures 10-15 clearly exhibit how the income distribution historically changed. For instance, the income distribution of Japan and USA tends to shift right side in spite of the decreasing $\alpha$ in Figure Annex. This change suggests the economic growth overcomes the expansion of the income inequity as a whole. We should analyze again whether this trend holds after the economic recession in 2009 when the income distribution data is available.

Different pattern can be seen in Figure 12, Brazil. Since the shape parameter $\alpha$ indicates less than 1.0 during the period, the population fraction of low income class remains large even if average income is increasing. In contrast, the former central planned economy countries tend to show high $\alpha$ in spite of the similar average income to Brazil. Figure 13, Hungary, shows small income inequity with low average value in 1980's and then shifts to right side suggesting that the middle to high income class is growing decreasing the low income people. Figure 14, Kenya, shows societal structure changes clearly. One can see the shift from lowest income class to the middle income class during 1987-1993. However, the income inequity seems to increase after 1998 since the 


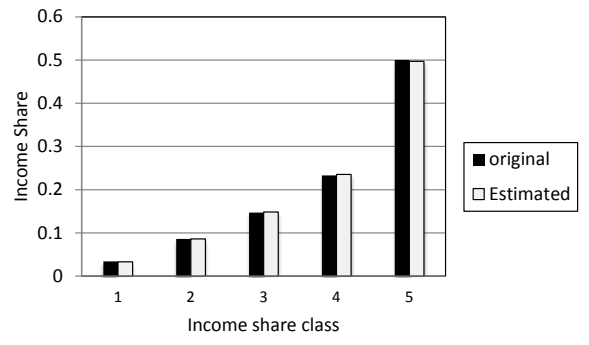

(a)

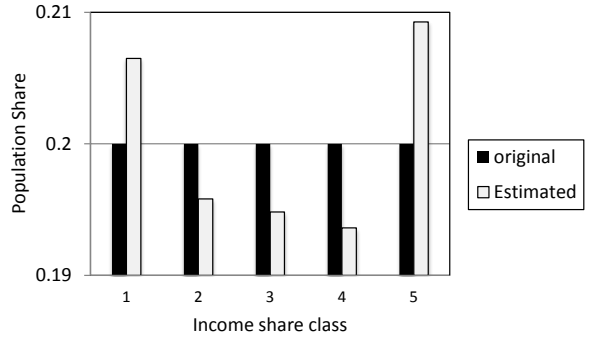

(b)

Figure 2. The original and the estimated income share histogram (USA, 2008). (a) Income share; (b) Population share. $\alpha$ : 1.29, $\beta$ : 530.4, $R^{2}: 1.000$. Class 1: lowest 20\%, Class 2: Second 20\%, Class 3: Third 20\%, Class 4: Fourth $20 \%$, Class 5: Hiest 20\%.

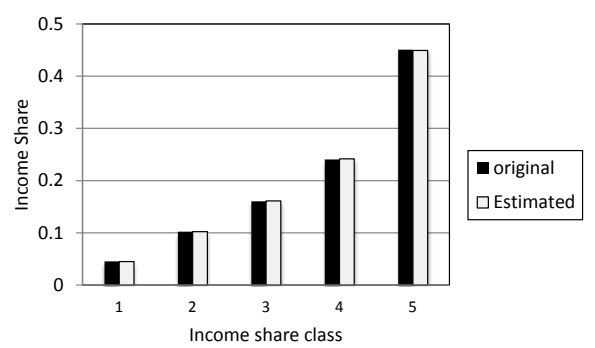

(a)

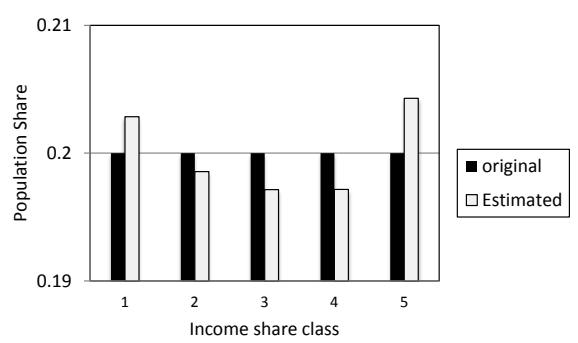

(b)

Figure 3. The original and the estimated income and population share histogram (Japan, 2006). (a) Income share; (b) Population share. $\alpha$ : 1.72, $\beta$ : 283.4, $R^{2}: 1.000$ SD. Class 1: lowest 20\%, Class 2: Second 20\%, Class 3: Third 20\%, Class 4: Fourth $20 \%$, Class 5: Hiest $20 \%$.

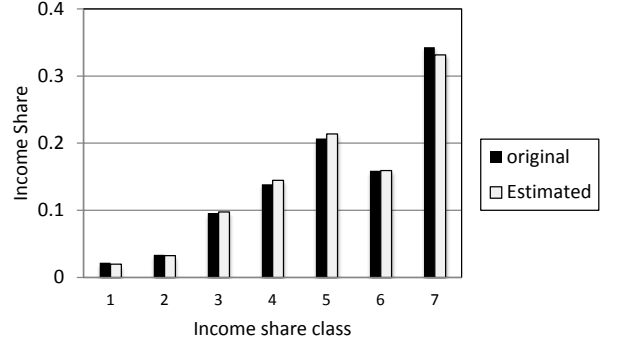

(a)

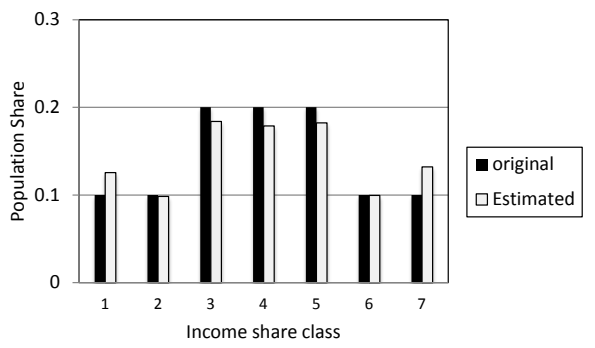

(b)

Figure 4. The original and the estimated income share histogram (Russia, 2007). (a) Income share; (b) Population share. $\alpha$ : $1.70, \beta$ : $53.6, R^{2}$ : 0.998. Class 1: lowest $10 \%$, Class 2: Second $10 \%$, Class 3: Third $20 \%$, Class 4: Fourth 20\%, Class 5: Fifth 20\%, Class 6: Sixth 10\%, Class 7: Highest $10 \%$.

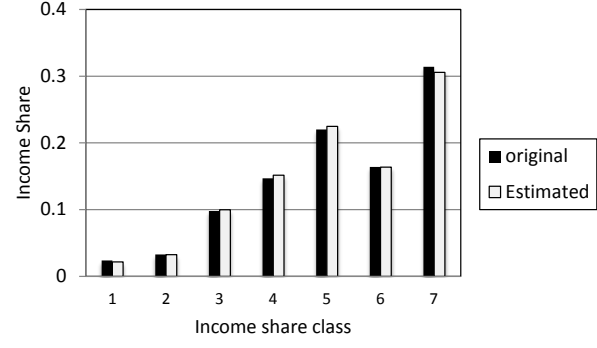

(a)

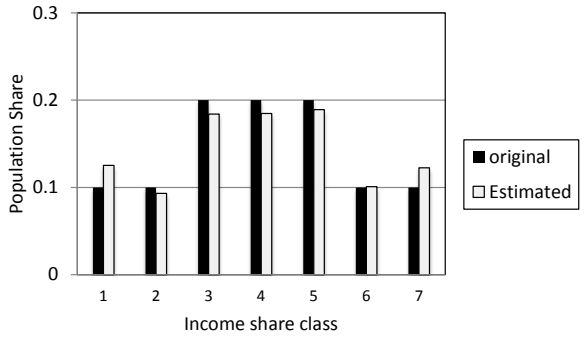

(b)

Figure 5. The original and the estimated income share histogram (China, 2005). (a) Income share; (b) Population share. $\alpha$ : 2.89, $\beta$ : 9.32, $R^{2}$ : 0.998. Class 1: lowest $10 \%$, Class 2: Second 10\%, Class 3: Third 20\%, Class 4: Fourth 20\%, Class 5: Fifth $20 \%$, Class 6: Sixth 10\%, Class 7: Highest $10 \%$. 


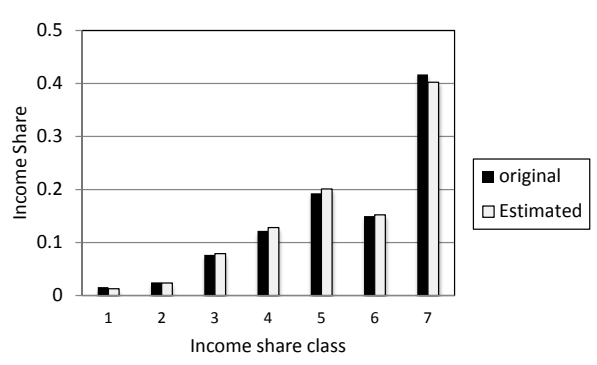

(a)

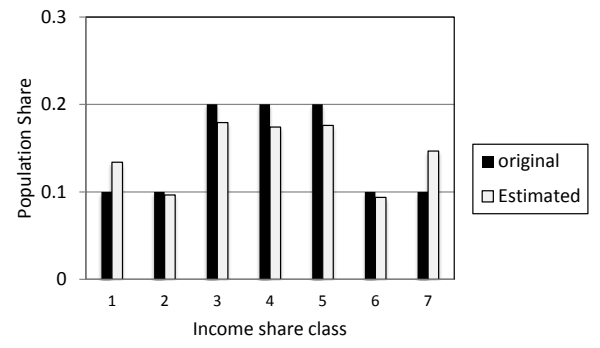

(b)

Figure 6. The original and the estimated income share histogram (Chile, 2006). (a) Income share; (b) Population share. $\alpha$ : 1.19, $\beta$ : 74.9, $R^{2}$ : 0.998. Class 1: lowest $10 \%$, Class 2: Second 10\%, Class 3: Third 20\%, Class 4: Fourth 20\%, Class 5: Fifth 20\%. Class 6: Sixth 10\%, Class 7: Highest $10 \%$.

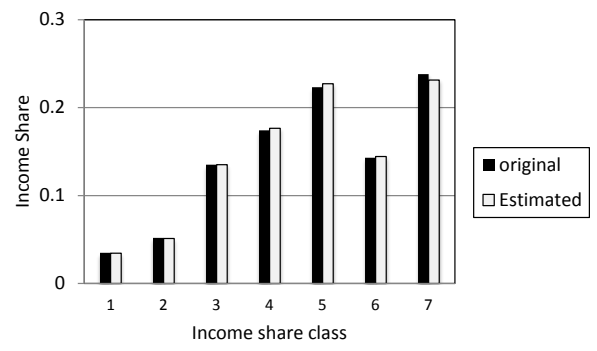

(a)

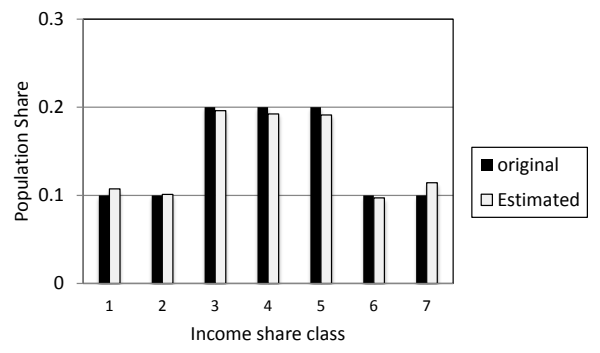

(b)

Figure 7. The original and the estimated income share histogram (Bulgaria, 2003). (a) Income share; (b) Population share. $\alpha$ : 3.79, $\beta$ : 6.74, $R^{2}$ : 0.998. Class 1: lowest $10 \%$, Class 2: Second $10 \%$, Class 3: Third 20\%, Class 4: Fourth 20\%, Class 5: Fifth $20 \%$. Class 6: Sixth 10\%, Class 7: Highest $10 \%$.

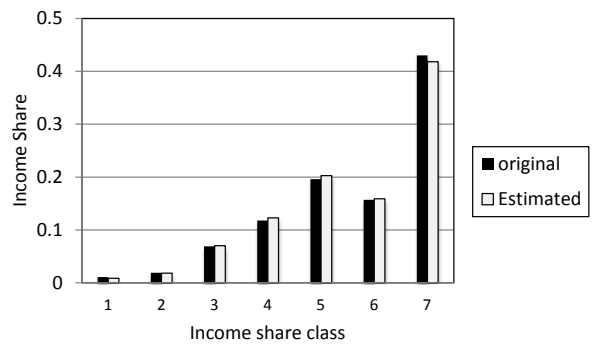

(a)

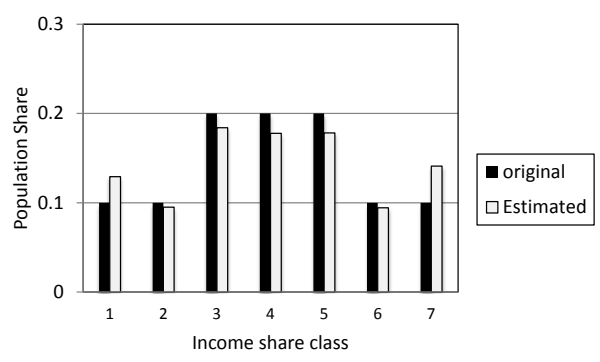

(b)

Figure 8. The original and the estimated income share histogram (Brazil, 2007). (a) Income share; (b) Population share. $\alpha$ : 1.00, $\beta$ : 70.1, $R^{2}$ : 0.999. Class 1: lowest $10 \%$, Class 2: Second 10\%, Class 3: Third 20\%, Class 4: Fourth 20\%, Class 5: Fifth 20\%, Class 6: Sixth 10\%, Class 7: Highest $10 \%$.

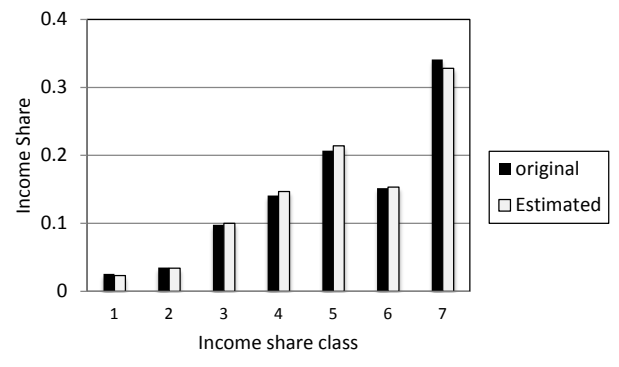

(a)

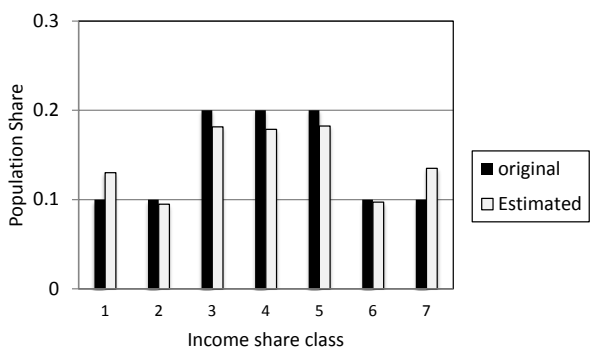

(b)

Figure 9. The original and the estimated income share histogram (Uganda, 2005). (a) Income share; (b) Population share. $\alpha$ : $1.84, \beta: 1.14, R^{2}: 0.997$. Class 1: lowest $10 \%$, Class 2: Second $10 \%$, Class 3: Third 20\%, Class 4: Fourth 20\%, Class 5: Fifth $20 \%$, Class 6: Sixth $10 \%$, Class 7: Highest $10 \%$. 


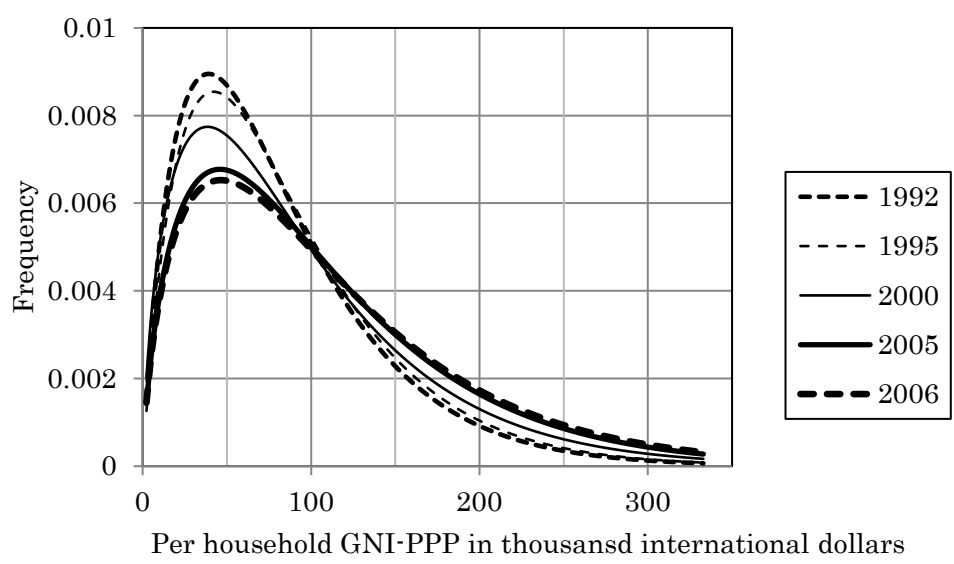

Figure 10. Income distribution changes of Japan for 1992-2006.

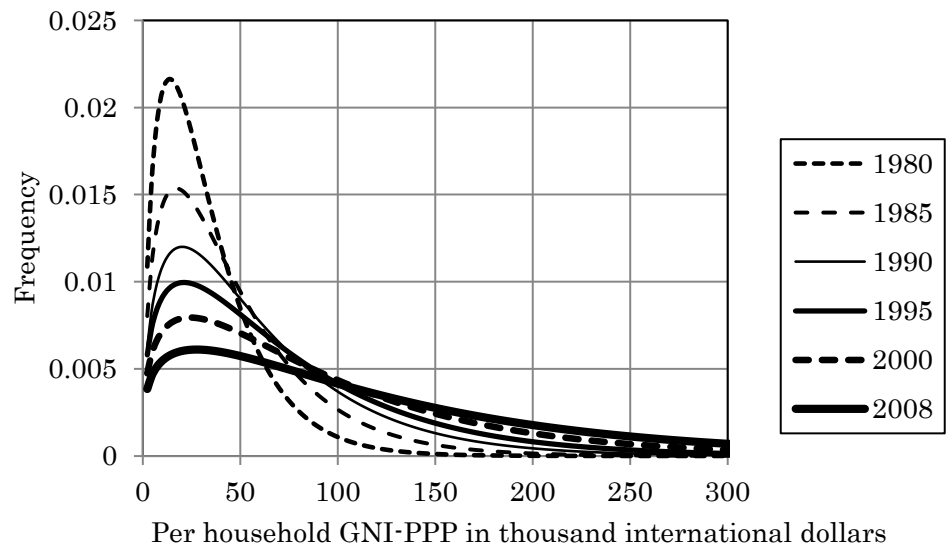

Figure 11. Income distribution changes of USA for 1980-2008.

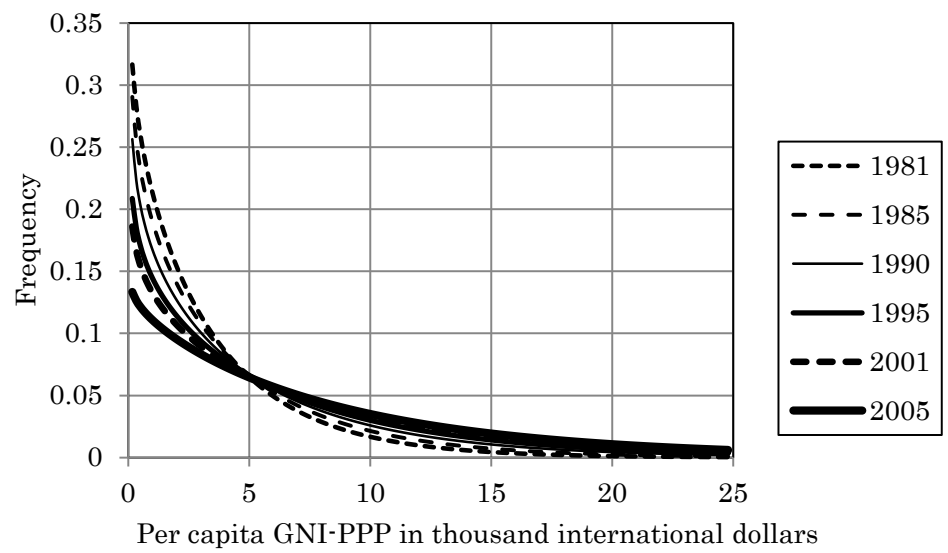

Figure 12. Income distribution changes of Brazil for 1981-2005.

peak of the distribution shift left side with increasing average income.

\subsection{Analysis of Shape Parameter $\alpha$ and Their Projection}

Shape parameter $\alpha$ of Gamma distribution is essential to see the income inequity. However, Figure 15 shows almost no significant relationship between per-capita income and $\alpha$. On the other hand, the results in Figure Annex suggest some qualitative observations. 1) former central planned economy countries tend to show high $\alpha$ 


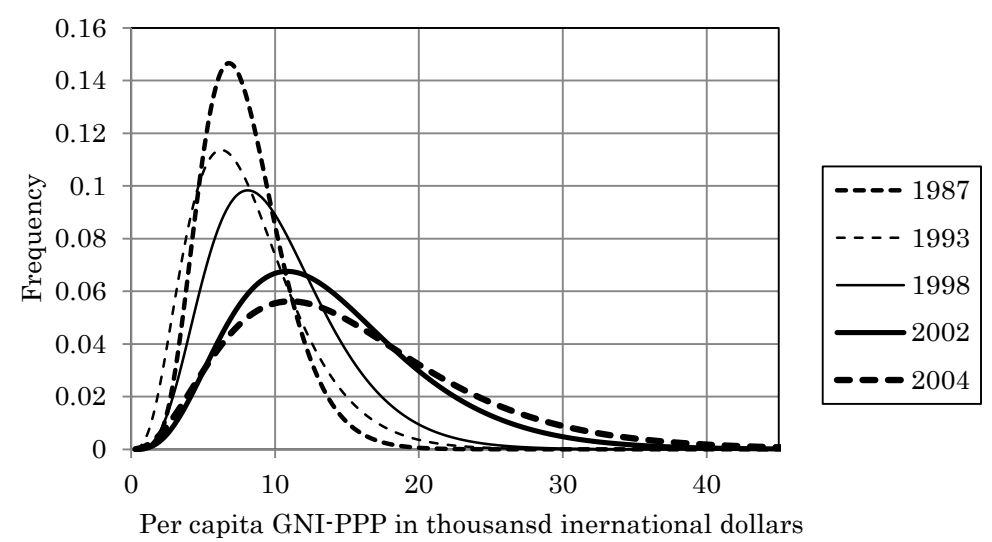

Figure 13. Income distribution changes of Hungary for 1987-2004.

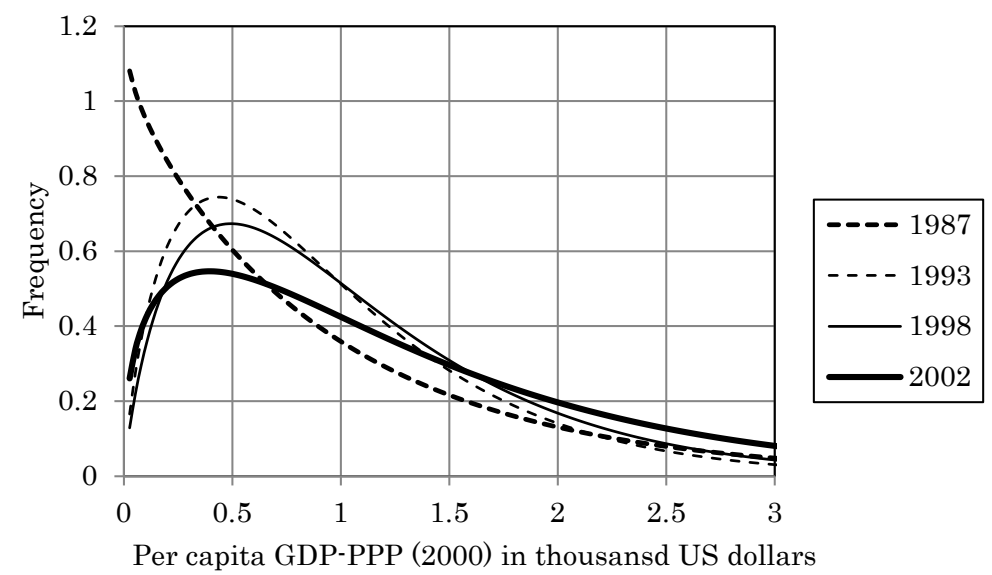

Figure 14. Income distribution changes of Kenya for 1987-2002.

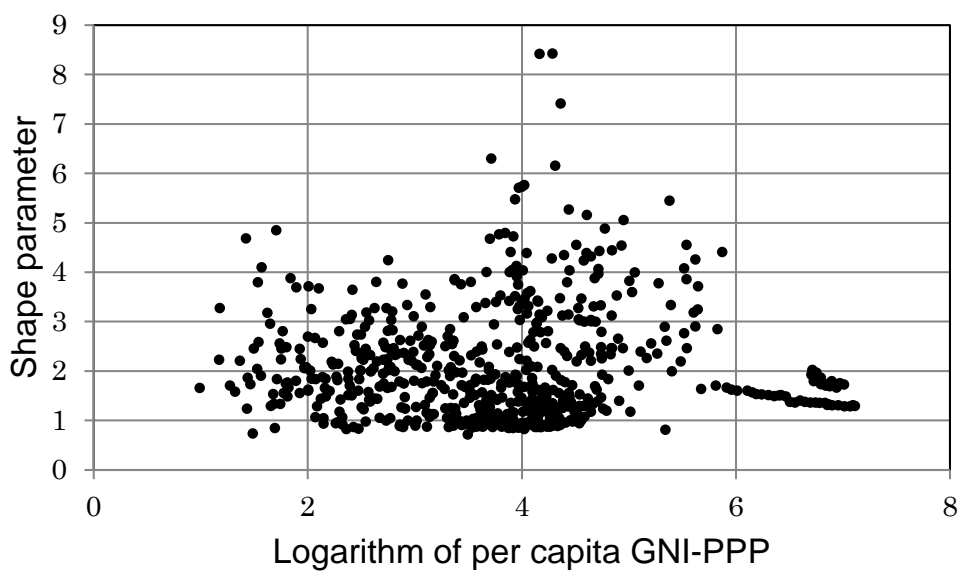

Figure 15. Relationship between per capita GNI-PPP vs. shape parameter $\alpha$.

values, 2) south-American countries tend to show low $\alpha$ values, and 3) middle income and developed countries tend to show almost constant values.

We apply the regression method in the following manner: firstly, we exclude the data of USA, Japan and OECD countries since we focus on the relationship between economic growth and income distribution. Second, we extract countries who provide more than five data points (four points for Africa) to see the effects of economic growth. Thus, we obtain 310 points for 46 countries. Third, we list possible explanatory variables such as 
industry structure, e.g. share of primary industry production in GDP and per capita income of agriculture industry, energy supply variables, e.g. share of electric power consumption in final energy use and power generation mix, and Human Development Index [17].

Here we employ the per capita GDP-PPP in 2000 value corresponding to the food market model GISELA [6] to assess the future food issue instead of GNI-PPP in current international dollars in Figure Annex. Adding various dummy variables and diminishing insignificant variables, we obtain the regression equation summarized in Table 2. Reflecting the variety of national conditions, dummy variables are imposed mostly for Africa and former central planned economy countries, which indicate significant positive values. This table suggests that economic growth basically increase the shape parameter decreasing the income inequity while regional and historical conditions cause significant difference. The original and the estimated value of $\alpha$ is visualized in Figure 16 implying the need for the deeper analysis of the income distribution structure in spite of the significant $R^{2}$. However, in this paper, we employ this equation for the projection of future food demand and supply gap.

\section{Projection of Future Income Distribution and Hunger Issues}

\subsection{Base Data Provided by GISELA Model}

In order to discuss the future food demand and supply issue, we need the assessment of future food supply and demand scenario taking into account the global climate changes, land use change and dietary shift. In this paper, we employ GISELA model results developed by the author [6]. GISELA-GIS based Evaluation for Land use and Agriculture production model-is formulated as an inter-temporal nonlinear optimization model with world 18 regions including the estimation of potential cropland for rice, wheat, maize and soybeans production under climate changes. The food and the feed demand are estimated based on the historical regional statistics. Figure 17 shows the outline of GISELA model. In GISELA model, the base line of food demand is estimated by GDPPPP while the international and the domestic market equilibrium on supply and prices is represented by GDP in real market exchange rate (GDP-MEX) to keep the trade balance consistency. In this study, we extract the scenario on GDP-PPP, GDP-MEX, population and market prices of major crops from GISELA simulation results.

Table 2. Results of regression analysis of shape parameter $\alpha$.

\begin{tabular}{cccc}
\hline & Coeff. & SD & t-value \\
Const. & 0.483 & 0.428 & 1.128 \\
Per Cap GDPppp & 0.167 & 0.056 & 2.969 \\
High Income_Dummy & -0.023 & 0.008 & -2.903 \\
EEP Dummy & 0.674 & 0.096 & 7.040 \\
Georgia_Dummy & -0.081 & 0.018 & -4.433 \\
Spain_Cln_Dummy & -0.067 & 0.086 & -7.495 \\
CPE_Dummy & 0.935 & 0.087 & 10.736 \\
Cote d'Ivoire_Dummy & 0.319 & 0.154 & 2.071 \\
Ethiopia_Dummy & 2.076 & 0.244 & 8.496 \\
Ghana_Dummy & 0.509 & 0.190 & 2.675 \\
Uganda_Dummy & 0.350 & 0.197 & 1.773 \\
Hungary_Dummy & 0.812 & 0.179 & 4.526 \\
Ukraine_Dummy & 1.079 & 0.173 & 6.257 \\
Belarus_Dummy & 0.976 & 0.151 & 6.449
\end{tabular}

$\widehat{R}^{2}=0.846$ total data $=310$. High Income_Dummy: $\ln$ (per capita income) is less than 8.85 then 0 otherwise ln(per capita income). EEP Dummy: 1 for European former central planned economy and 0 for others. Georgia_Dummy: 1 for Georgia and 0 for others. Spain_Cln_Dmmy: 1 for former colonies of Spain and 0 for others. CPE Dummy: 1 for former central planned economy and 0 for others. Cote d'Ivoire_Dummy: 1 for Cote d'Ivoire and 0 for others. Ethiopia_Dummy: 1 for Ethiopia and 0 for others. Ghana_Dummy: 1 for Ghana and 0 for others. Uganda_Dummy: 1 for Uganda and 0 for others. Hungary_Dummy: 1 for Hungary and 0 for others. Ukraine_Dummy: 1 for Ukraine and 0 for others. Belarus_Dummy: 1 for Belarus and 0 for others. 


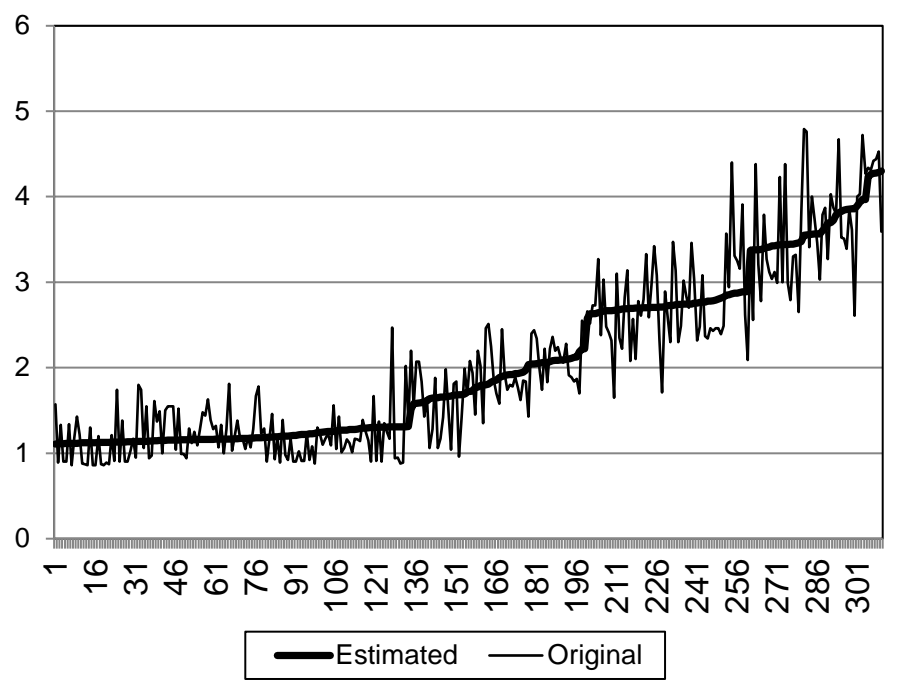

Figure 16. Regression results of shape parameter $\alpha$ : original and estimated.

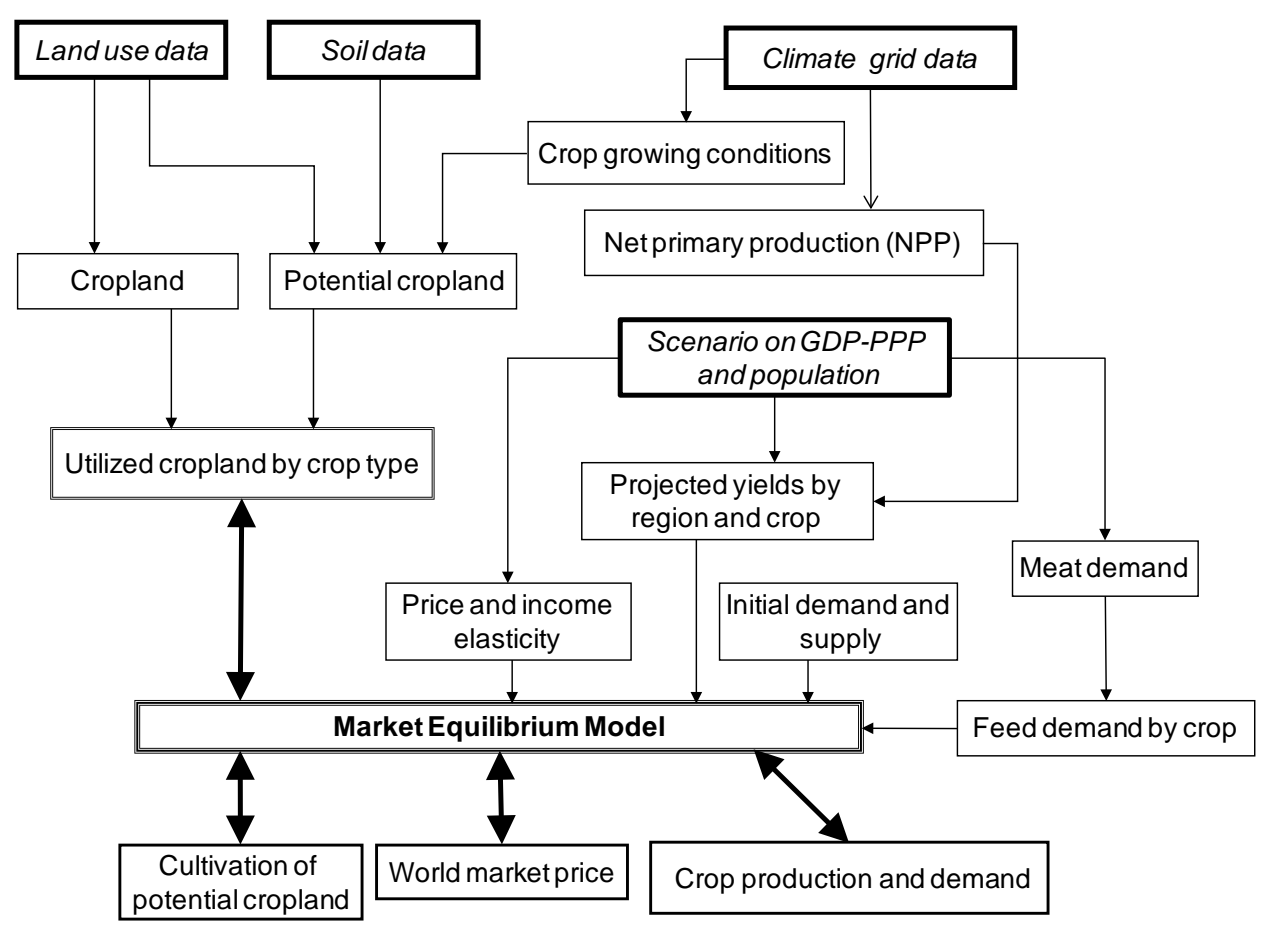

Figure 17. Outline of GISELA model [6].

Based on the future average per-capita income in GDP-PPP, we evaluate the changes of $\alpha$. We then calculate $\beta$ based on GDP-MEX projection.

Figure 18 shows the example of the projection of income distribution of Brazil for 2010 to 2050. The fraction of middle to high income class tends to increase as the economic grows continuously. Figure 19 exhibits the example of regional market price of maize given by GISELA for 2000-2050.

\subsection{Estimation of Poverty: Population under $\$ 1.25$ per Day Income}

In this subsection, we apply the above Gamma distribution to the estimation of poverty and hunger as a preliminary calculation to see the possibility of this method. Based on the Gamma distribution and the population pro- 
jections, we can calculate the population below $\$ 1.25$ per day income [11] as shown in Figure 20. It should be noted that the income is given in GDP-MEX in 2000 rather than the GDP-PPP. This figure shows the population in absolute poverty will significantly decrease, but the decreasing rates differ among regions. In China and South-Asian, poverty decreases more rapidly than other regions while Central Africa and South-Africa seem to take longer time to overcome the poverty.

This figure shows that the population under \$1.25 per day income in 2005 is 425 million, while World Bank [11] counts 958 million.

Table 3 compares the population in poverty estimated by World Bank and those by our model. This shows the difference between two mainly comes from South Asia countries and China. On the other hand, countries in Africa and South-America seem to represent harmonized numbers.

We can be consider two reasons. First, the Gamma distribution is not applicable to the actual distribution when the distribution density has multiple peaks. Figure Annex shows that shape parameters in India and China are around 2.0 suggesting the existence of single peak. However, when "true" income distribution has another peak in the lowest income class, our method cannot capture this second one. Second, since our method based on the income share of population indicated by deciles or quintiles estimated based on the households survey, the

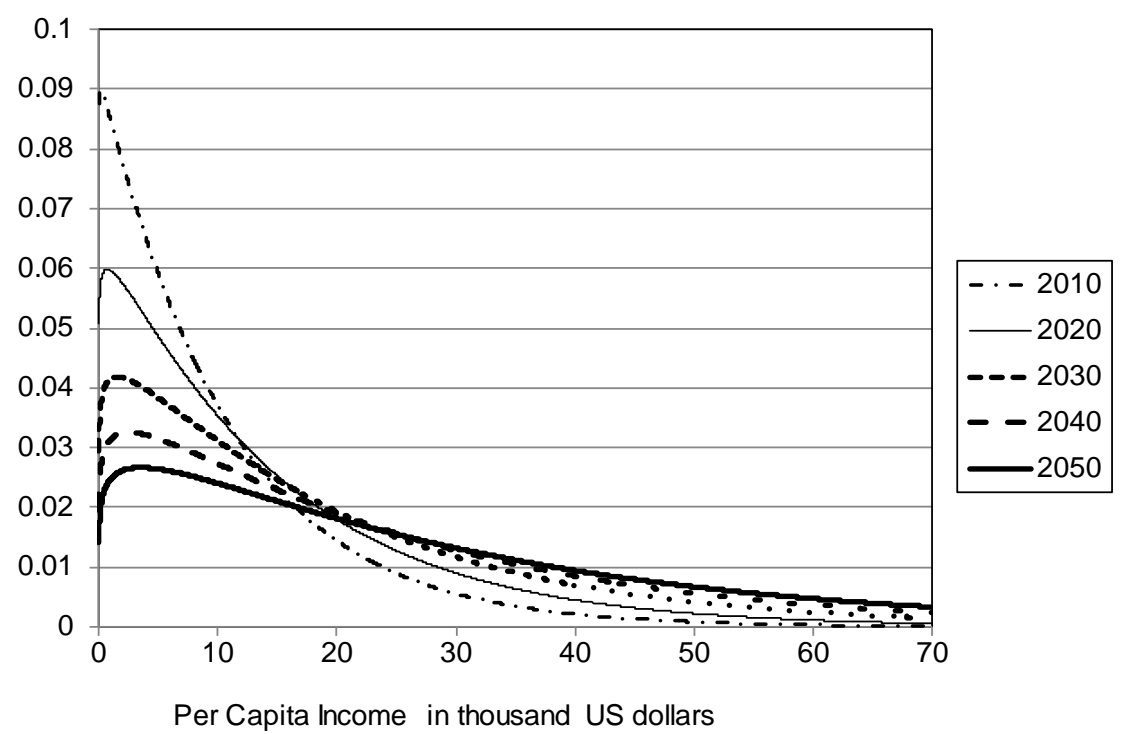

Figure 18. Example of projected future income distribution; Brazil for 2010-2050. GDP is represented in GDP-PPP in 2000 US dollars.

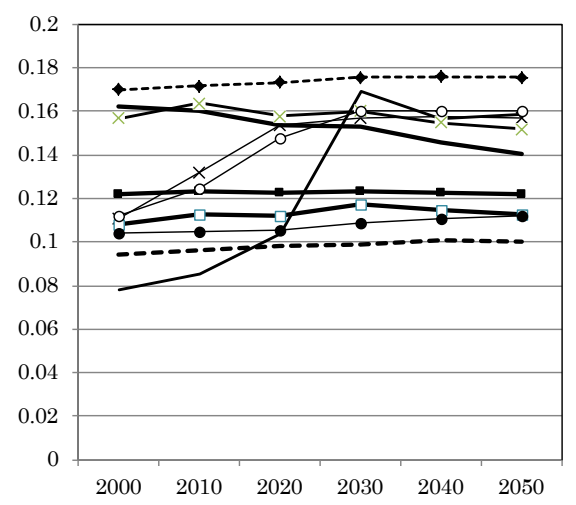

(a)

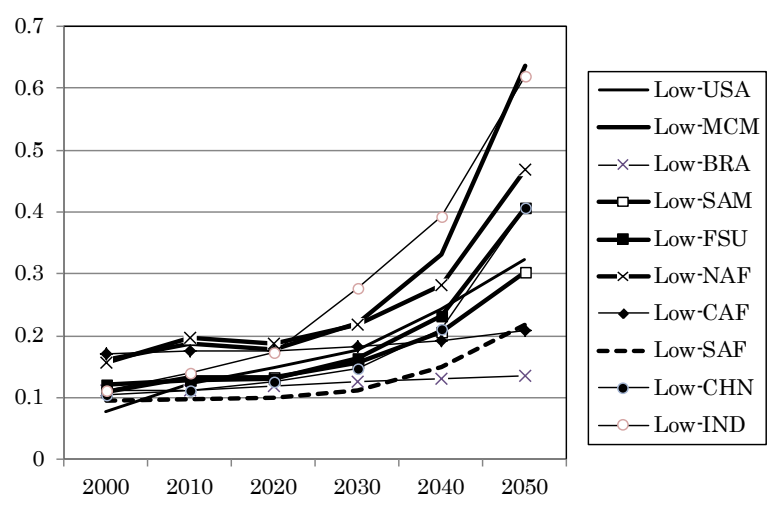

(b)

Figure 19. Projection of maize domestic market price in dollars per kg by GISELA. (a) Middle yield case; (b) Low yield case. 


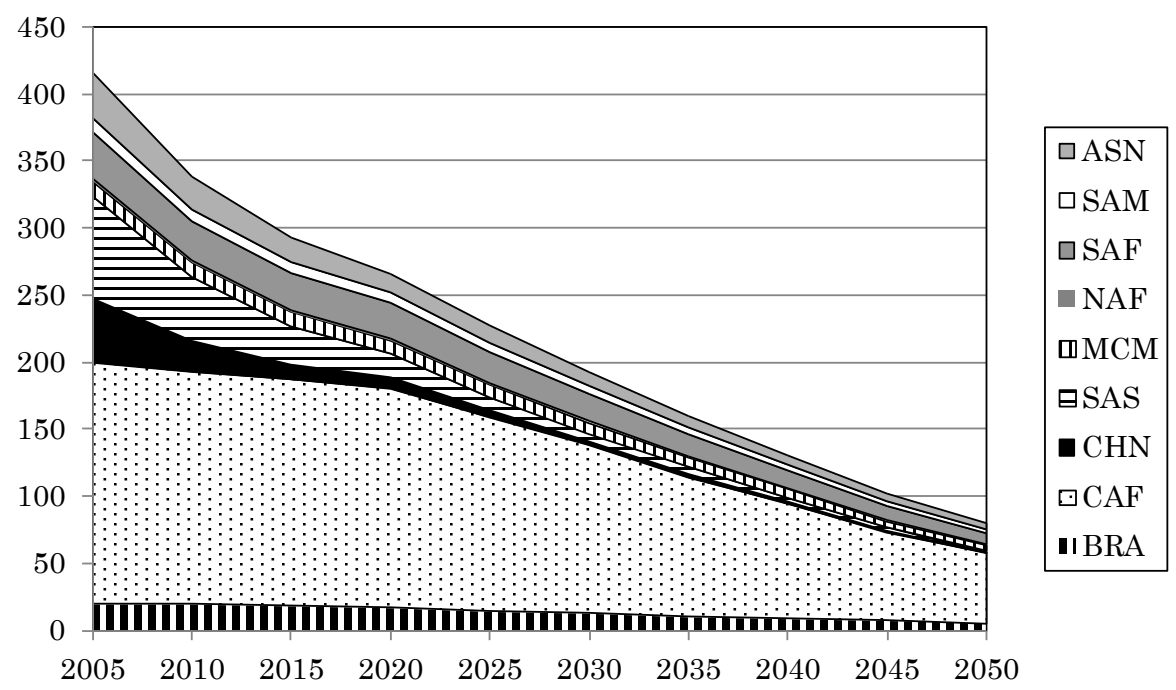

Figure 20. Estimation of poverty population below \$1.25 (GDP in $2000 \mathrm{MEX)}$ a day income. ASN: East-South Asian countries; SAM: South-American countries; SAF: South-African countries; NAF: North-African countries; MCM: Mexico and Central American countries; SAS: South Asian countries; CHN: China; CAF: Central-African countries; BRA: Brazil.

Table 3. Comparison of poverty population below \$1.25 (GDP in $2000 \mathrm{MEX)} \mathrm{a} \mathrm{day} \mathrm{income.}$

\begin{tabular}{cccccccccc}
\hline & World & India & China & Bangladesh & Indonesia & Pakistan & Ethiopia & Brazil \\
\hline World Bank & 958.0 & 474.7 & 211.9 & 71.0 & 48.7 & 35.8 & 28.9 & 15.8 \\
Model & 425.1 & 58.1 & 46.9 & 14.3 & 5.3 & 4.2 & 33.3 & 19.6 \\
\hline & Kenya & Madagascar & Niger & Colombia & Senegal & Yemen & Venezuela & Peru \\
\hline World Bank & 15.45 & 12.13 & 6.52 & 5.47 & 3.64 & 3.62 & 3.57 & 2.36 \\
Model & 7.93 & 5.62 & 6.00 & 4.07 & 1.22 & 5.84 & 0.01 & 1.63 \\
\hline
\end{tabular}

reliability of our method substantially firstly depends on the coverage of this survey. The above consideration suggests that there are many poor people who are not included in the survey. Further investigation will be needed to evaluate the income gap. Shape parameter $\alpha$ of Gamma distribution is essential to see the income inequity. However, Figure 15 shows almost no significant relationship between per-capita income and $\alpha$. On the other hand, the results in Figure Annex suggest some qualitative observations.

\subsection{Estimation of Population in Hunger}

GISELA generates domestic market prices on maize, rice and wheat as shown in Figure 19. In this study we assess the population who cannot afford minimum crop, i.e. $2000 \mathrm{kcal}$ per day per person, at market. Assuming the weight of maize, rice and wheat of $2000 \mathrm{kcal}$ to be $2 \mathrm{~kg}, 0.56 \mathrm{~kg}$ and $0.543 \mathrm{~kg}$, respectively, we calculate the minimum requirement of crop per year. Multiplying the minimum annual requirement of crop by the crop price projections of GISELA, we estimate the minimum expenditure for food. Since minimum income level to live on must be larger than this, we hypothetically assume the border of hunger to be the twice of this minimum crop expenditure. We can then calculate the fraction of people whose income level is insufficient to afford the crop at the market based on the Gamma distribution. The estimation results are summarized in Figures 21-23. One observes that although the population in hunger is decreasing towards 2050, the decreasing rates vary among regions. In CHN and SAS in Figure 22, population in hunger decreases rapidly thanks to the economic growth while those in Africa and South America regions show relatively lower decreasing rate. In the low yield case, although those in CAF and CHN still decreases, SAS, SAM, MCM and NAF show very slow decreasing pattern. It should be noted that USA, MCM and Japan indicate increasing numbers due to the decreasing tendency of $\alpha$ in spite of the high income level. 


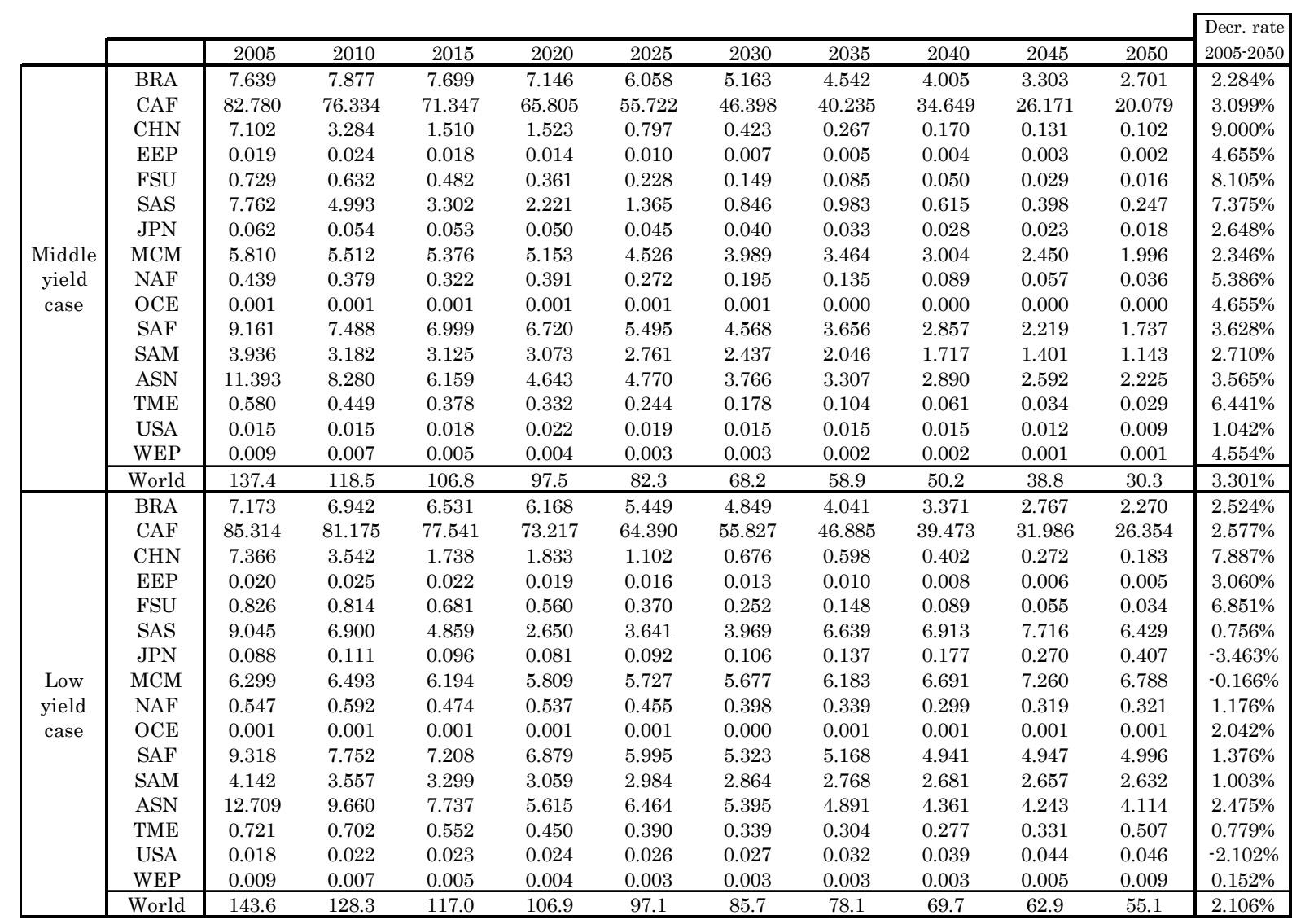

Figure 21. Summary of estimated population with insufficient income level in million. BRA: Brazil; CAF: Central Africa countries; CHN: China; EEP: former Eastern Europe countries; FSU: former Soviet Union; SAS: South Asia countries; JPN: Japan; MCM: Mecico and Central America; NAF: North Africa; OCE: Australia and New Zealand; SAF: South Africa; SAM: South America; ASN: East-South Asian; TME: Turkey and Middle-East; USA: United States; WEP: Other European countries.

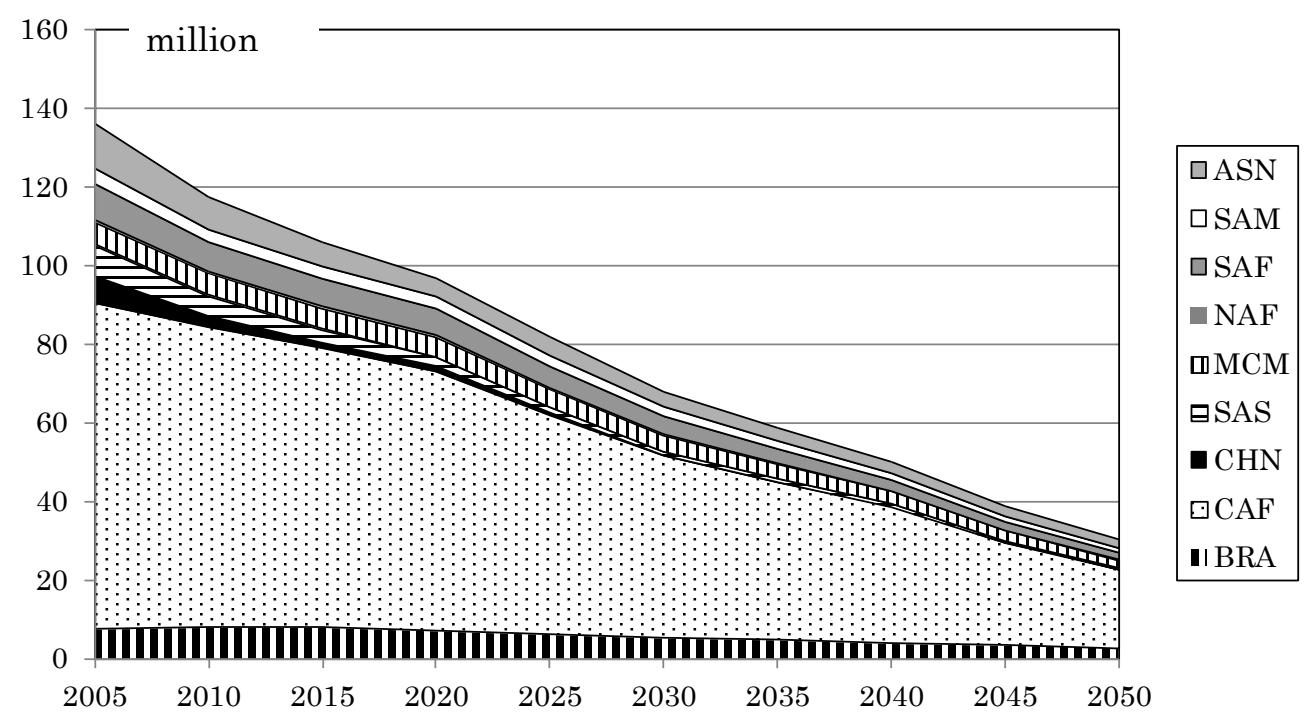

Figure 22. Profile of population with insufficient income: middle yield case. ASN: East-South Asian countries; SAM: South-American countries; SAF: South-African countries; NAF: North-African countries; MCM: Mexico and Central American countries; SAS: South Asian countries; CHN: China; CAF: Central-African countries; BRA: Brazil. 


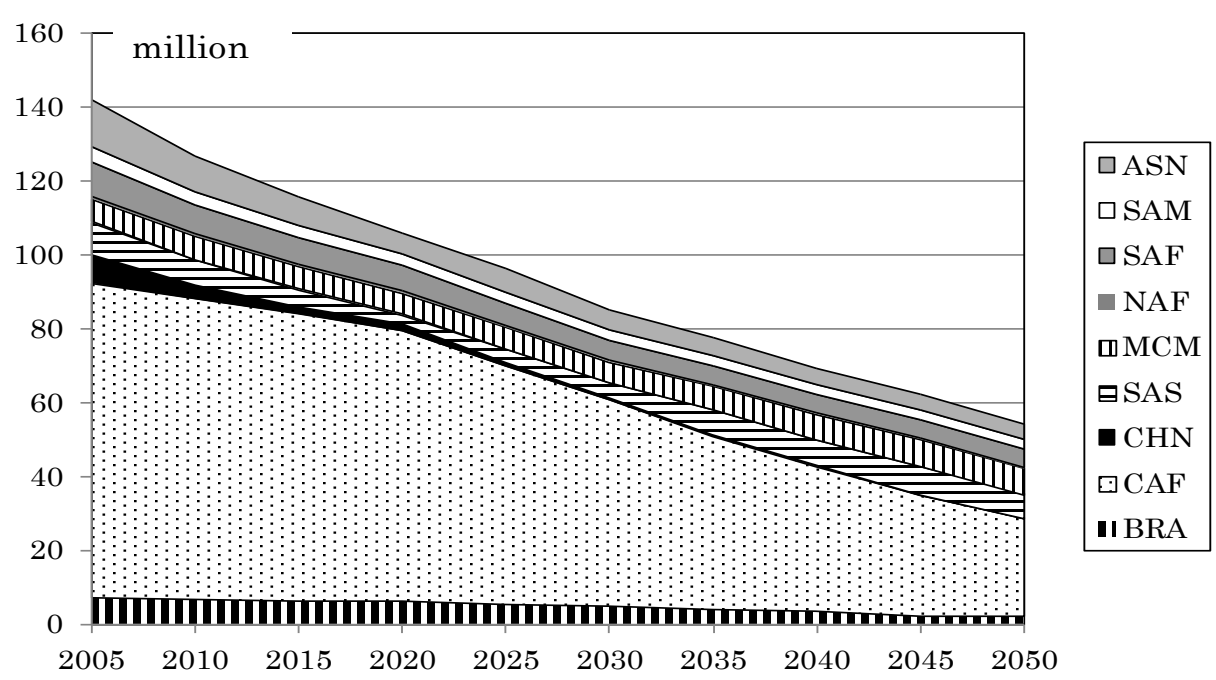

Figure 23. Profile of population with insufficient income: low yield case. ASN: East-South Asian countries; SAM: South-American countries; SAF: South-African countries; NAF: NorthAfrican countries; MCM: Mexico and Central American countries; SAS: South Asian countries; CHN: China; CAF: Central-African countries; BRA: Brazil.

It should be pointed out that Food and Agriculture Organization (FAO, 2010) estimates the number of undernourished people in the world to be 850 million in 2005 while that in our study is 140 million. There are some possible reasons of this discrepancy: first, the Gamma distribution is not applicable to the actual distribution when the distribution density has multiple peaks. Population in the lowest income class could be overlooked by the application of Gamma distribution. Second, the coverage of household survey might have overlooked people suffering from hunger as pointed out in the previous section. Many people who are excluded from the household could be suffering from hunger. Third, our definition of the border of hunger could be still optimistic. For instance, market price of crop would be much lower than the food.

On the other hand, our procedure based on income is not appropriate for the farmers who supply their food by themselves. Since our study focuses on the macro level statistics, further discussion is needed to look into the structure of income distribution, especially on the lowest income group.

\section{Conclusions}

In this paper, we propose a method to evaluate the income distribution directly from the income share quantile data applying Gamma distribution function to see the income inequity issues more concretely. We could estimate the parameters with fairly high fitness for 622 income data developing an estimation procedure. Although the largest two countries, i.e. China and India, do not provide the time series data, the estimated shape parameters show some interesting historical patterns. For instance, former Eastern Europe countries show high $\alpha$ numbers representing low inequity of income while former colonies of Spain tend to show low values. African countries show diverging results on shape parameters reflecting the historical and political conditions.

We then apply the Gamma distribution to the estimates of population in absolute poverty and compare them to the World Bank's report. Our estimate of the population below the $\$ 1.25$ per day income is 425 million in 2005 while World Bank evaluates it to be 958 million. This discrepancy mainly comes from the China and South-Asian countries. The Gamma distribution function and the household survey could have overlooked the people who are in poverty.

We also evaluate the population in hunger by defining the fraction of insufficient income class to purchase the crop of minimum nutrition. Based on the crop market model GISELA results, we estimate the population in hunger by country. Although the results for 2005 show underestimated values comparing with those of FAO, future changes of the population in hunger suggest the variety of regional behavior.

In this stage, since the results of our method do not harmonize with those of the existing estimates, further investigation will be needed to look into the details of the income distribution and inequity issue. Nonetheless, we 
would conclude that the method proposed here will provide useful research basis to this field since the income distribution provides various information and application frontiers.

\section{References}

[1] FAO (2010) Global Hunger Declining, but Still Unacceptably High. http://www.fao.org/docrep/012/al390e/al390e00.pdf

[2] Piketty, T. (2013) Le Capital au XXI ${ }^{\mathrm{e}}$ Siecle, Seuil, Capital in the Twenty-First Century. Harvard University Press, Cambridge.

[3] World Bank (2012) http://data.worldbank.org/indicator/SI.POV.GINI/

[4] World Bank (2012) http://data.worldbank.org/indicator/SI.DST.FRST.20/

[5] World Bank (2012) http://data.worldbank.org/indicator/SI.DST.02ND.20/

[6] Mori, S., Kato, M. and Ido, T. (2010) GISELA—GIS-Based Evaluation of Land Use and Agriculture Market Analysis under Global Warming. Applied Energy, 87, 236-242. http://dx.doi.org/10.1016/j.apenergy.2009.06.013

[7] Brown, L.R. (2005) Outgrowing the Earth: The Food Security Challenge in an Age of Falling Water Tables and Rising Temperatures. W.W. Norton \& Co, NY, USA.

[8] IFPRI (2008) Reaching Sustainable Food Security for All by 2020. http://www.ifpri.org/2020/books/actionlong.pdf

[9] Kawashima, H. (2008) World Food Production and Biomass Energy. Tokyo University Press, Tokyo. (In Japanese)

[10] Lomborg, B. (2001) The Skeptical Environmentalist: Measuring the Real State of the World. Cambridge University Press, Cambridge. http://dx.doi.org/10.1017/CBO9781139626378

[11] World Bank (2012) http://data.worldbank.org/indicator/SI.DST.03RD.20/

[12] World Bank (2012) http://data.worldbank.org/indicator/SI.DST.04TH.20/

[13] World Bank (2012) http://data.worldbank.org/indicator/SI.DST.05TH.20/

[14] World Bank (2012) http://data.worldbank.org/indicator/SI.DST.10TH.10/

[15] USDC (2010) US Department of Commerce. http://www.census.gov/hhes/www/income/data/historical/inequality/index.html

[16] MIAC (2010) Ministry of Internal Affairs and Communication. http://www.stat.go.jp/data/kakei/kyokai.htm

[17] UNDP (2011) Human Development Index. http://hdr.undp.org/en/statistics/ 
Figure Annex. Example of Gamma Distribution Estimated Results Extracted from 583 Cases

\begin{tabular}{|c|c|c|c|c|c|c|c|c|c|}
\hline Year & Country & $\alpha$ & $B$ & $\mathrm{R} 2$ & Year & Country & $\alpha$ & $B$ & $\mathrm{R} 2$ \\
\hline 2001 & Brazil & 0.87 & 36.02 & 0.999 & 1987 & Chile & 0.98 & 17.03 & 0.998 \\
\hline 2002 & Brazil & 0.87 & 32.36 & 0.999 & 1990 & Chile & 1.02 & 23.46 & 0.998 \\
\hline 2003 & Brazil & 0.89 & 34.19 & 0.999 & 1994 & Chile & 1.03 & 37.77 & 0.998 \\
\hline 2004 & Brazil & 0.9 & 40.11 & 0.999 & 1996 & Chile & 1.04 & 49.79 & 0.998 \\
\hline 2005 & Brazil & 0.95 & 49.91 & 0.999 & 1998 & Chile & 1 & 52.78 & 0.998 \\
\hline 2006 & Brazil & 0.97 & 59.67 & 0.999 & 2000 & Chile & 1.03 & 47.36 & 0.998 \\
\hline 2007 & Brazil & 1 & 70.13 & 0.999 & 2003 & Chile & 1.07 & 43.34 & 0.998 \\
\hline 2003 & Benin & 2.25 & 2.15 & 0.996 & 2006 & Chile & 1.19 & 74.90 & 0.998 \\
\hline 1992 & Kenya & 0.96 & 3.42 & 0.998 & 1986 & Bangladesh & 4.68 & 0.43 & 0.996 \\
\hline 1994 & Kenya & 1.81 & 1.48 & 0.998 & 1992 & Bangladesh & 4.84 & 0.54 & 0.998 \\
\hline 1997 & Kenya & 1.84 & 2.45 & 0.997 & 1996 & Bangladesh & 3.69 & 0.84 & 0.995 \\
\hline 2005 & Kenya & 1.42 & 3.68 & 0.998 & 2000 & Bangladesh & 3.67 & 0.91 & 0.995 \\
\hline 2007 & Liberia & 2.22 & 0.91 & 0.997 & 2005 & Bangladesh & 3.64 & 1.08 & 0.994 \\
\hline 1989 & Uganda & 1.58 & 1.95 & 0.998 & 1984 & Malaysia & 1.35 & 16.79 & 0.998 \\
\hline 1992 & Uganda & 1.86 & 0.81 & 0.996 & 1987 & Malaysia & 1.45 & 13.36 & 0.998 \\
\hline 1996 & Uganda & 2.45 & 1.14 & 0.996 & 1989 & Malaysia & 1.51 & 14.61 & 0.998 \\
\hline 1999 & Uganda & 1.8 & 1.41 & 0.997 & 1992 & Malaysia & 1.39 & 22.29 & 0.998 \\
\hline 2002 & Uganda & 1.62 & 1.46 & 0.996 & 1995 & Malaysia & 1.34 & 32.19 & 0.998 \\
\hline 2005 & Uganda & 1.84 & 1.70 & 0.997 & 1997 & Malaysia & 1.31 & 35.29 & 0.998 \\
\hline 1993 & South Africa & 0.84 & 41.43 & 0.999 & 2004 & Malaysia & 2.2 & 22.53 & 0.999 \\
\hline 1995 & South Africa & 0.97 & 39.82 & 0.998 & 1981 & Thailand & 1.6 & 4.51 & 0.997 \\
\hline 2000 & South Africa & 0.89 & 33.93 & 0.999 & 1988 & Thailand & 1.75 & 6.39 & 0.997 \\
\hline 2005 & China & 1.84 & 9.32 & 0.999 & 1992 & Thailand & 1.58 & 12.12 & 0.997 \\
\hline 1996 & Hong Kong & 1.61 & 153.42 & 0.998 & 1996 & Thailand & 1.77 & 16.96 & 0.997 \\
\hline 1989 & Bulgaria & 5.72 & 4.28 & 0.884 & 1998 & Thailand & 1.93 & 9.44 & 0.997 \\
\hline 1992 & Bulgaria & 3.41 & 3.56 & 0.998 & 1999 & Thailand & 1.74 & 11.40 & 0.997 \\
\hline 1994 & Bulgaria & 5.47 & 2.10 & 0.998 & 2000 & Thailand & 1.78 & 11.06 & 0.997 \\
\hline 1995 & Bulgaria & 3.03 & 5.15 & 1.000 & 2002 & Thailand & 1.89 & 10.53 & 0.997 \\
\hline 1997 & Bulgaria & 4.79 & 2.60 & 0.997 & 2004 & Thailand & 1.85 & 13.36 & 0.997 \\
\hline 2001 & Bulgaria & 2.56 & 6.72 & 0.999 & 1992 & Japan & 1.92 & 266.41 & 1.000 \\
\hline 2003 & Bulgaria & 3.79 & 6.74 & 0.998 & 1993 & Japan & 2.02 & 292.73 & 1.000 \\
\hline 1993 & Belarus & 6.29 & 2.53 & 0.865 & 1994 & Japan & 1.79 & 363.04 & 1.000 \\
\hline 1995 & Belarus & 3.8 & 3.61 & 0.999 & 1995 & Japan & 1.96 & 357.78 & 1.000 \\
\hline 1997 & Belarus & 4.67 & 2.99 & 1.000 & 1996 & Japan & 1.76 & 345.37 & 1.000 \\
\hline 1998 & Belarus & 3.52 & 4.29 & 0.998 & 1997 & Japan & 1.74 & 312.43 & 1.000 \\
\hline 2000 & Belarus & 3.51 & 3.63 & 0.998 & 1998 & Japan & 1.86 & 269.11 & 1.000 \\
\hline 2001 & Belarus & 3.39 & 3.66 & 0.999 & 1999 & Japan & 1.73 & 317.64 & 1.000 \\
\hline 2002 & Belarus & 3.61 & 4.07 & 0.999 & 2000 & Japan & 1.7 & 336.72 & 1.000 \\
\hline 2005 & Belarus & 4.03 & 7.67 & 0.999 & 2001 & Japan & 1.73 & 286.35 & 1.000 \\
\hline 2007 & Belarus & 3.87 & 12.06 & 0.999 & 2002 & Japan & 1.69 & 278.07 & 1.000 \\
\hline 1993 & Russian Federation & 1.35 & 21.70 & 0.999 & 2003 & Japan & 1.79 & 279.33 & 1.000 \\
\hline 1996 & Russian Federation & 1.45 & 18.29 & 0.998 & 2004 & Japan & 1.66 & 323.15 & 1.000 \\
\hline 1999 & Russian Federation & 2.2 & 6.09 & 0.998 & 2005 & Japan & 1.75 & 292.34 & 1.000 \\
\hline 2001 & Russian Federation & 2.02 & 10.40 & 0.998 & 2006 & Japan & 1.72 & 283.35 & 1.000 \\
\hline 2002 & Russian Federation & 2.46 & 9.67 & 0.998 & 1995 & United States & 1.4 & 320.98 & 1.000 \\
\hline 2005 & Russian Federation & 2.25 & 23.74 & 0.999 & 1996 & United States & 1.37 & 343.96 & 1.000 \\
\hline 2007 & Russian Federation & 1.7 & 53.60 & 0.998 & 1997 & United States & 1.36 & 365.38 & 1.000 \\
\hline 1984 & Mexico & 1.46 & 16.28 & 0.998 & 1998 & United States & 1.36 & 381.28 & 1.000 \\
\hline 1992 & Mexico & 1.2 & 35.08 & 0.998 & 1999 & United States & 1.35 & 405.46 & 1.000 \\
\hline 1994 & Mexico & 1.18 & 39.91 & 0.998 & 2000 & United States & 1.35 & 423.22 & 1.000 \\
\hline 1996 & Mexico & 1.33 & 27.04 & 0.998 & 2001 & United States & 1.31 & 441.62 & 1.000 \\
\hline 1998 & Mexico & 1.28 & 34.55 & 0.999 & 2002 & United States & 1.32 & 440.97 & 1.000 \\
\hline 2000 & Mexico & 1.17 & 50.73 & 0.998 & 2003 & United States & 1.3 & 454.36 & 1.000 \\
\hline 2002 & Mexico & 1.29 & 50.31 & 0.998 & 2004 & United States & 1.3 & 465.12 & 1.000 \\
\hline 2004 & Mexico & 1.46 & 50.97 & 0.998 & 2005 & United States & 1.28 & 494.88 & 1.000 \\
\hline 2006 & Mexico & 1.39 & 65.50 & 0.998 & 2006 & United States & 1.28 & 520.08 & 1.000 \\
\hline 2008 & Mexico & 1.17 & 87.45 & 0.998 & 2007 & United States & 1.3 & 520.07 & 1.000 \\
\hline & & & & & 2008 & United States & 1.29 & 530.42 & 1.000 \\
\hline
\end{tabular}

$\left(^{*}\right)$ Scaling parameter $\beta$ is calculated based on GNI-PPP in current hundred international dollars. $\left(^{* *}\right)$ SD represents the standard deviation of the estimated population share. 